\title{
Reassessing the validity of AS3959 in the presence of dynamic bushfire propagation
}

\author{
$\underline{\text { J.J. Sharples }}^{\text {a }}$ and R.P. Cechet ${ }^{\text {a }}$ \\ ${ }^{a}$ School of Physical, Environmental and Mathematical Sciences, UNSW Canberra. \\ Email:.j.sharples@adfa.edu.au
}

\begin{abstract}
The Australian Standard for construction of buildings in bushfire-prone areas (AS3959) specifies requirements in order to improve the resistance of buildings against bushfire attack from burning embers, radiant heat, direct flame contact, or a combination of these three factors. In particular, AS3959 informs the design and construction of buildings in bushfire-prone areas through the concept of Bushfire Attack Level (BAL). In principle, BAL can be determined through application of the Standard to any site in the landscape, thereby providing the appropriate design and construction measures required to reduce the risk of bushfire igniting a building situated at the site. The calculation of BAL at a site relies on the following four main factors:
\end{abstract}

- fire danger;

- vegetation type;

- distance of the site from the classified vegetation; and

- the topographic slope on which the vegetation is situated.

Moreover, BAL is calculated based on the assumption that a fire will behave in accordance with the quasisteady assumption. In this paper we examine the validity of AS3959 in situations where the quasi-steady assumption is violated. In these situations the expectation is that fires will exhibit dynamic modes of fire spread such as vorticity-driven lateral spread, eruptive fire spread and ember storms. As such, this study constitutes a critical review of the current models and methods informing the construction of buildings in bushfire prone regions, and that underpin bushfire risk assessment on the urban interface more broadly.

We find that there are a number of recent insights into dynamic fire behaviour that are not adequately addressed in the modelling framework that underpins AS3959. For example, current calculation of BAL is based on radiation thresholds derived using (scalar) distance to vegetation as a key input, without any acknowledgement of directional influences. A case study is presented that highlights the fact that dynamic modes of propagation could produce a strong directional bias on bushfire attack levels. The overall implication is that construction standards and bushfire risk more generally, as assessed based on the principles espoused in AS3959, is likely to be under-predicted in the presence of dynamic fire propagation. The insights gained from recent dynamic fire modelling efforts provide the basis for further review and refinement of AS3959.

Keywords: Bushfire risk, Australian Standard, dynamic fire behaviour, AS3959 


\section{INTRODUCTION}

Bushfire is part of Australia's natural environment. Historically, bushfires have sporadically, but consistently, resulted in significant environmental and socio-cultural impacts. In particular, over the last few decades, major bushfires have impacted the ex-urban margins of Sydney, Canberra, and Melbourne, burning more than a million hectares of forests and woodlands and causing devastating loss of life and property. In total, there have been over 200 lives and 4000 homes lost across southern Australia since 2003. Other bushfire-related losses include cultural heritage, important infrastructure (e.g. power lines and substations, scientific facilities), and psychological stress suffered by firefighters and members of the public.

The losses caused by large bushfires over the last decade or so have prompted questions about the changing nature of bushfire events and how they impact densely populated areas. In particular, concern is centred on the occurrence or perception of a shift to a significantly more hazardous fire regime, characterised by increasing fire frequency and intensity associated with dynamic fire propagation, and the development of catastrophic 'firestorms'. Given the likely effects of climate change, the expectation is that large destructive fires will become more prevalent in the future (Sharples et al. 2016). This trend, combined with the increasing expansion of urban centres into wildland areas, will present an increasingly challenging problem to land managers and fire agencies.

In order to ameliorate the impacts caused by large bushfires, a number of protective measures have been developed and implemented. These include: enhanced hazard reduction programs (e.g. prescribed burning), revised public warning systems, and improved building design and construction guidelines combined with better informed urban planning. Bushfire science plays a key role in informing these measures and ensuring that they represent best practice. However, given the nature of the scientific process and the difficulties associated with altering statutory regulations, there is often a lag between what is accepted as best practice in bushfire risk management and the state of the science.

In this paper we consider the current regulatory guidelines designed to mitigate the risk of bushfire. In particular, we review the current Australian Standard for construction of buildings in bushfire prone areas and highlight a number of shortcomings that relate to recent insights into dynamic fire behaviour. A consequence of these shortcomings is that the likelihood of bushfire igniting a structure may be significantly under-predicted in areas that are prone to dynamic fire behaviours. We illustrate this using the Ginninderry region in NSW $\left(35.20^{\circ} \mathrm{S}, 148.96^{\circ} \mathrm{E}\right)$, as a case study to examine the potential for increased levels of bushfire risk, above what would be implied based on the current guidelines. This region is of interest as it is currently subject to land rezoning, with the ultimate intention of housing around 30,000 people.

\section{AUSTRALIAN STANDARD (AS 3959) AND BUSHFIRE ATTACK LEVELS}

The Australian Standard for construction of buildings in bushfire-prone areas (AS3959, Standards Australia (2009)) specifies requirements in order to improve the resistance of buildings against bushfire attack from burning embers, radiant heat, direct flame contact, or a combination of these three factors. As such it provides a framework designed to ameliorate the likely impacts of bushfire through better design and construction of buildings.

AS3959 informs the design and construction of buildings in bushfire-prone areas through the concept of Bushfire Attack Level (BAL). In principle, BAL can be determined through application of the Standard to any site in the landscape, thereby providing the appropriate design and construction measures required to reduce the likelihood of bushfire igniting a building situated at the site.

The calculation of BAL at a site relies on the following four main factors:

- $\quad$ Fire danger index (in the present context this is provided by Forest Fire Danger Index (FFDI));

- Vegetation type;

- $\quad$ Distance of the site from the classified vegetation (sites $>100 \mathrm{~m}$ from vegetation are excluded);

- The topographic slope on which the vegetation is situated.

The fire danger index is used on a regional basis for calculation of flame height and fire line intensity, which then facilitate calculation of the level of radiant heat impacting a structure. In the present context an FFDI of 80 (NSW) is used. Of particular note is that the calculation of flame height and fire line intensity under AS3959 explicitly assumes that the fire is spreading in a quasi-steady manner. It has been acknowledged that the assumption of quasi-steady fire spread is of extremely limited validity under extreme conditions (e.g. Bushfire CRC Black Saturday Fire Behaviour Report, 2009; Cruz et al. 2012). 
The vegetation type, in which a fire is burning, influences several fire behaviour characteristics including rate of spread and flame length. Implementation of the Standard requires that vegetation is categorised into one of twenty-eight different vegetation classes. The vegetation class is then combined with information on fuel loads to determine expected rate of spread, fire line intensity and flame length. These fire behaviour characteristics are then used to estimate the radiant heat flux presented by the flames.

The distance between the site, the intervening slope and the vegetation classes are used to calculate the radiation view factor as well as the atmospheric transmissivity of the radiant heat. These quantities are combined to calculate the amount of radiant heat exposure of the site.

The topographic slope $S$ of the terrain on which the classified vegetation is situated is used to determine the expected rate of spread of the fire, which as mentioned above is used to estimate the radiant heat fluxes. This slope is not to be confused with the slope of the terrain that lies between the vegetation and the site, which is used only in the calculation of the radiation view factor.

BAL categories are defined in Table 3.1 of AS3959 in terms of radiative heat exposure thresholds. Table 3.1 also provides a brief description of the level of ember attack that could be expected in accordance with each of the BAL categories. In summary these are as follows:

- $\quad$ BAL-LOW: No mention of ember attack in Table 3.1;

- BAL-12.5: Table 3.1 simply states 'Ember attack' without any further quantification of ember intensity;

- BAL-19, BAL-29 and BAL-40: Table 3.1 states 'Increasing levels of ember attack and burning debris ignited by windborne embers...';

- BAL-FZ: Table 3.1 states that the structure will experience 'Direct exposure to flames [...] and ember attack'. Again, no further specific information is provided on the ember intensities that might be expected.

Overall, Table 3.1 seems to imply that the threat to a structure from ember attack is related to the radiant heat exposure of the structure. However, the nature of this relationship is unclear; other than the loose implication that an increase in radiant heat exposure should result in an increase in the chance of ember attack, there is no specific information on how ember attack is related to radiant heat exposure. Indeed, there does not appear to be any peer-reviewed literature (or any literature of which the authors are aware) that supports this implication, and it is easy to conceive of situations where ember intensity and radiant heat exposure are not strongly related. Figure 1 shows the 2003 Canberra fire impacting the suburb of Duffy, ACT as an ember storm. Of note is the high density of embers impacting structures and the distance of the structures from the main front of active flame.

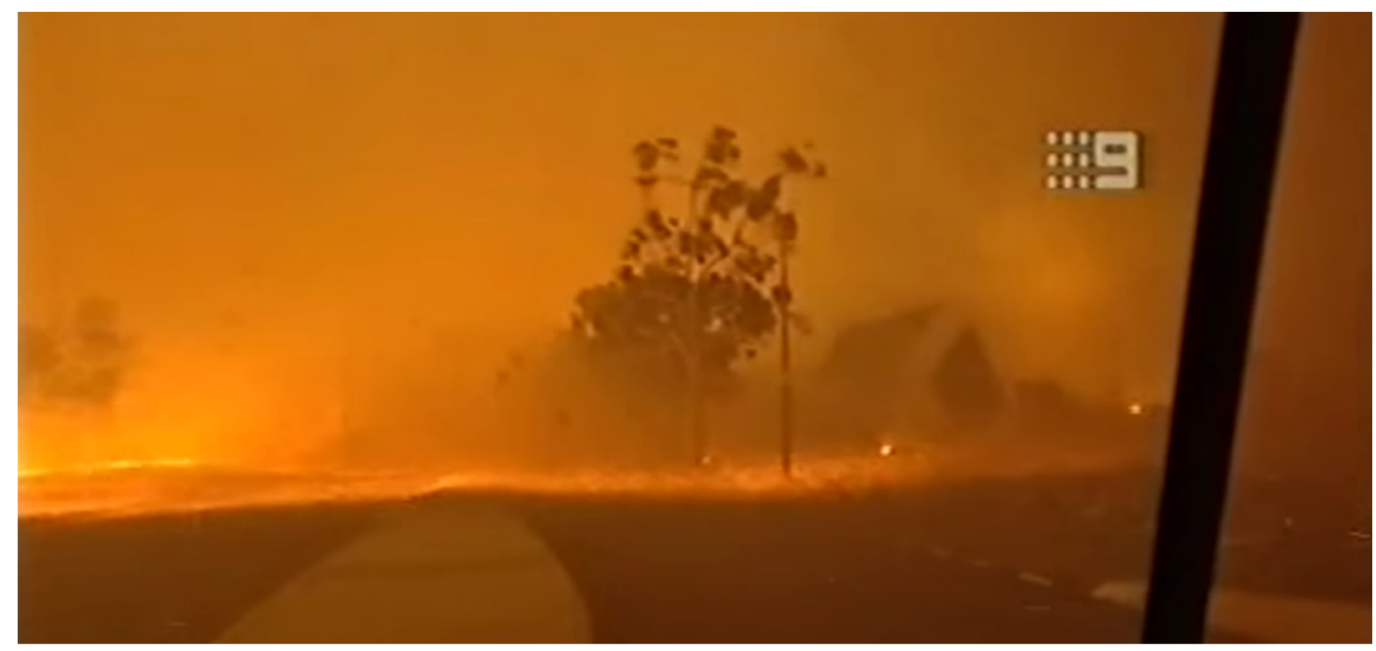

Figure 1. Ember storm impacts Duffy, 18 January 2003. The image is a still taken from the footage captured by Channel 9 cameraman R. Moran.

AS3959 also underpins determination of an Asset Protection Zone (APZ) in NSW, which is a set-back distance or buffer between vegetation and built assets. According to the NSW RFS guidelines for planning for bushfire protection (NSW RFS 2006), an APZ is intended "to provide sufficient space and maintain reduced fuel loads, so as to ensure radiant heat levels at buildings are below critical limits and to prevent 
direct flame contact with a building". An APZ ensures that built assets are separated from the bushfire hazard (i.e. the vegetation), thereby minimising the impact of radiant heat, and the likelihood of direct flame contact and ember attack. An APZ also provides a region from which firefighters can work more safely and effectively to suppress fire.

\section{RISK IMPLICATIONS OF DYNAMIC FIRE BEHAVIOUR}

As mentioned, the assumption of quasi-steady fire spread is of limited validity, particularly when it comes to understanding the local drivers of bushfire risk and the broader development of large, destructive bushfires. Recent research into bushfire risk has gone beyond the traditional (quasi-steady) research paradigm. Indeed, a new paradigm that acknowledges the dynamic nature of fire spread in the landscape has emerged over the last decade or so. This new approach has already provided a number of important insights into the local drivers of bushfire risk, and has highlighted the role of environmental factors that are significant for large fire development. These factors include aspects of the vertical structure of the atmosphere (Mills and McCaw, 2010), meso-scale fire weather processes (Peace et al. 2012), modifications of fire weather conditions by the local topography (Sharples, 2009; Sharples et al. 2012) and interactions between the fire and the atmosphere (Simpson et al. 2013; 2016). Here we focus on two particular types of dynamic fire spread that are relevant to the region surrounding Ginninderry.

\subsection{Eruptive fire behaviour}

Fires burning in steep and confined terrain have been shown to exhibit exponential increases in rate of spread, despite burning under unchanging environmental conditions (Viegas, 2005; Dold and Zinoviev, 2009). This phenomenon has been termed eruptive fire spread or fire eruption. Eruptive fire spread arises due to an interaction between the slope of the terrain and the fire's plume, which results in attachment of the fire's plume to the terrain surface. Numerical and laboratory experimentation has shown that in the absence of wind, plume attachment can be expected on terrain that is inclined at roughly $24^{\circ}$ or more. The particular geometry of the terrain will cause some variation about this threshold value, and the effects of wind could result in plume attachment at much lower threshold inclinations. AS3959 currently considers that convective heat transfer only becomes a contributing factor for inclinations above $30^{\circ}$, well above the threshold beyond which plume attachment might be expected.

The acceleration of the head fire in eruptive fire occurrences results in a deepening of the flaming zone; that is, it produces a larger area of active flame, from which heat is released into the atmosphere. Deep flaming has been associated with the development of violent pyroconvection and enhanced production and lofting of embers. This mode of fire propagation is also different from that expected under the quasi-steady fire spread paradigm, and has been associated with several firefighter fatalities (Viegas, 2009). Even in cases where lives are not lost, it is clear that eruptive fire behaviour poses a serious threat to the successful containment of a bushfire and provides a mechanism that can substantially elevate the risk posed by a bushfire in areas that are prone to its occurrence. Most importantly in the context of AS3959, flame attachment, which is driven by convective heat transfer, invalidates the current approach to calculating BAL based on radiative heat thresholds up to inclinations of $30^{\circ}$ (AS3959, Method 2).

\subsection{Vorticity-driven lateral spread}

Analyses of fire propagation during the 2003 Canberra fires revealed the existence of an atypical mode of fire spread (Sharples et al, 2012). This mode of fire spread is characterised by:

- Rapid lateral spread of a fire across a lee-facing slope in a direction that is nearly perpendicular to the prevailing winds;

- Fire spread constrained on the upwind edge by a significant break in topographic slope;

- Dense spotting and downwind extension of the flaming zone (for up to several kilometres);

- Dark, turbulent smoke (with cumuliform appearance) on the advancing flank

Simpson et al. (2013) found that the key driver of the phenomenon was the generation of pyrogenic vorticity; that is, the interaction of the winds, the terrain and the fire causes the generation of significant fire whirls on lee-facing slopes, which carry the fire laterally. Hence the terminology: vorticity-driven lateral spread (VLS). The existence of the VLS phenomenon has also been confirmed in a series of laboratory experiments conducted in Portugal and the USA, and in numerous post-2003 wildfire observations.

Sharples et al, (2012) found that the parts of the landscape prone to VLS occurrence are characterised by wind and terrain conditions satisfying $\chi=1$, where: 


$$
\chi(S, \alpha, \theta)=\left\{\begin{array}{cc}
1 & \text { if } S \geq 20^{\circ} \text { and }|\theta-\alpha| \leq 40^{\circ} \\
0 & \text { otherwise. }
\end{array}\right.
$$

Here $S$ is the topographic slope, $\alpha$ is the topographic aspect and $\theta$ is the direction the wind is blowing (e.g. for a westerly wind, $\theta=90^{\circ}$ ). In simple terms, the wind-terrain filter identifies parts of the terrain that are both sufficiently steep and sufficiently lee facing. In addition, wind speeds of about $20 \mathrm{~km} \mathrm{~h}^{-1}$ are required for VLS occurrence (Simpson et al. 2016). It is worth noting that AS3959 does not presently accommodate VLS, as it considers any downslope as flat.

\section{CASE STUDY OF THE GINNINDERRY REGION}

To examine the potential impact of dynamic fire spread on the level of bushfire risk at Ginninderry we assume a northwesterly wind. This is a reasonable assumption as in this region the highest risk of bushfire is associated with winds from that direction. Moreover, in accordance with the stipulations of AS3959, which assumes an FFDI of 80 or more to assess the level of construction standard, we assume that the winds are stronger than $20-25 \mathrm{~km} \mathrm{~h}^{-1}$. This puts the wind speed above the threshold required for VLS occurrence. Figure 2 shows the regions surrounding Ginninderry that are prone to VLS occurrence, as determined by equation (1).

Figure 2 indicates that the region immediately to the northwest of Ginninderry is particularly prone to VLS occurrence. As such, any fire that occurred in this region on a day of FFDI $\geq 80$ would be highly likely to exhibit VLS. This type of fire propagation has been associated with intense fire behaviour and the development of deep convective plumes (McRae et al. 2015). This type of fire behaviour would be markedly different from that assumed to occur under AS3959, and as such, the guidance based on the BAL classification may significantly underestimate the risk of bushfire to the northwestern boundary of the Ginninderry region.

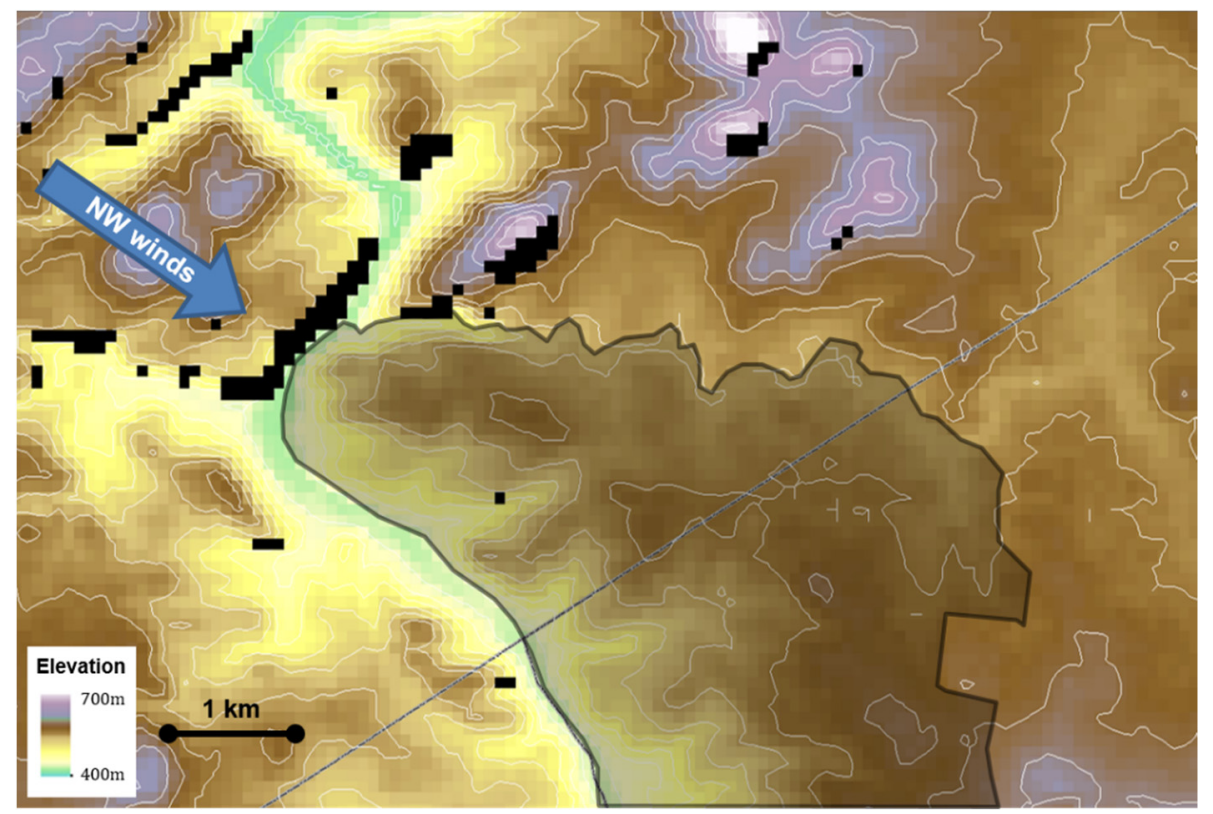

Figure 2. Map of elevation around the Ginninderry region, with the Ginninderry region in dark shading. The black pixels indicate locations prone to VLS occurrence under north-westerly winds, as determined using equation (1).

The steep slopes associated with the river corridors to the north and west of the Ginninderry region also raise concerns about the potential for eruptive fire behaviour. Even in the absence of wind the steep slopes in the area would be prone to flame attachment. The red pixels in Figure 3 highlight slopes greater than about $24^{\circ}$. Such slopes exceed the threshold inclination of about $24^{\circ}$ required for flame attachment to occur. Given that AS3959 considers an FFDI of 80, and assuming reasonable bounds on temperature and relative humidity, winds should be considered as strong (e.g. $>25 \mathrm{~km} \mathrm{~h}^{-1}$ ). Under such conditions, flame attachment would be expected on slopes that are inclined less than $24^{\circ}$. While research is yet to provide definitive guidance on how wind affects the threshold inclination for flame attachment, it should be expected that under strong winds, slopes as low as $20^{\circ}$, which are aligned with the winds, would experience flame attachment. 
The west facing slopes circled in blue in Figure 3 would be of particular concern in the development of fire originating to the northwest of the Ginninderry region. Under strong northwesterly winds and with low fuel moisture content, a bushfire would escalate considerably on these slopes and create extensive regions of intense flaming. Violent pyroconvection would be highly likely under such a circumstance and the land downwind of these slopes would be blanketed with thousands of embers producing multiple spot fires. Again, under such conditions the expected fire behaviour would be quite different to the quasi-steady fire behaviour assumed under AS3959. Moreover, as mentioned above, the plume attachment associated with eruptive fire behaviour means that radiative heat fluxes would be dominated by convective heat fluxes. The overall implication is that in regions prone to VLS or eruptive fire behaviour, the level of bushfire attack at a structure could be significantly underestimated using the BAL classification.

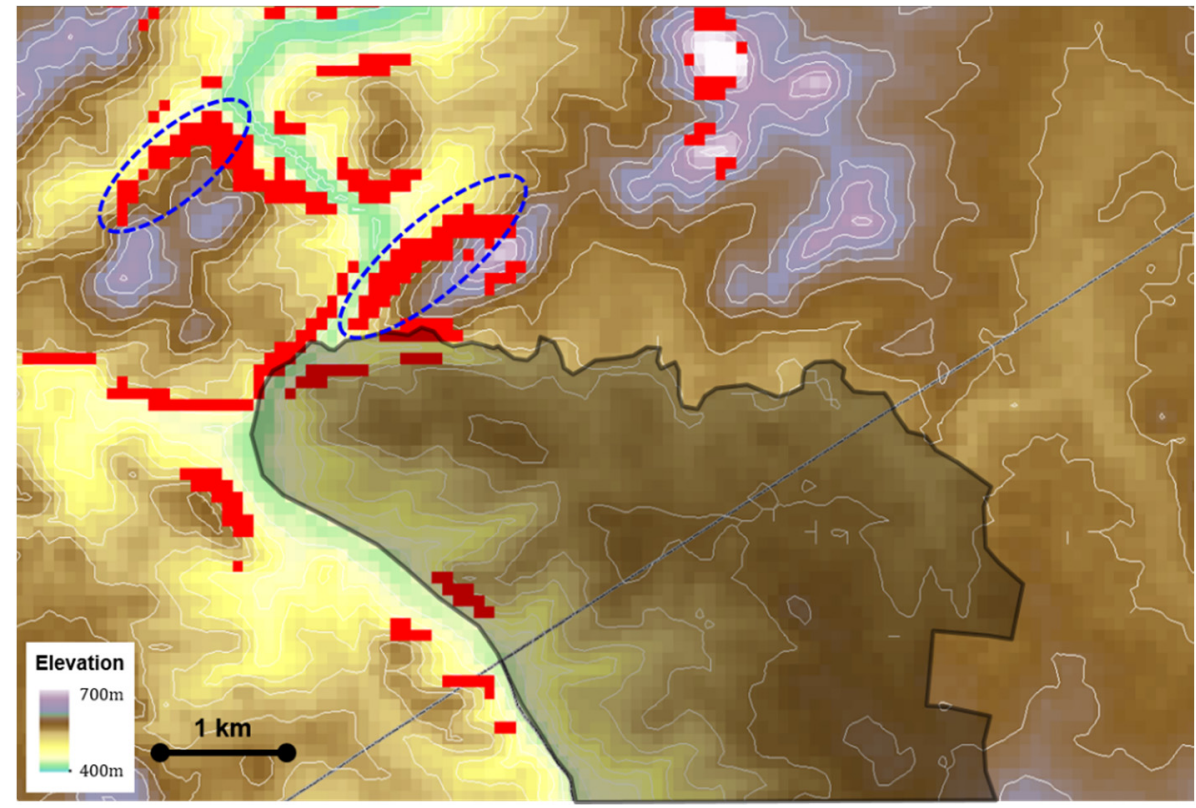

Figure 3. Map of elevation around the Ginninderry region, with the Ginninderry region in dark shading. The red pixels indicate locations with slopes above about $24^{\circ}$, and highlight the potential for eruptive fire behaviour (in the absence of wind).

\subsection{Impacts of embers}

The propensity for dynamic modes of fire propagation to occur to the northwest of the Ginninderry region means that fires originating in this area would likely produce dense swarms of embers. Consequently, rather than spreading as a contiguous flame front like that perceived to impact built assets in AS3959, fires originating to the northwest of the Ginninderry region under extreme conditions would more likely propagate as a series of coalescing spot fires. The steep southeast facing slopes to the northwest of Ginniderry would likely generate a significant number of embers if VLS was to occur. Roberts et al. (2017) provide an indication of the likely pattern of ember attack (both short-range and long-range) on the Ginninderry region arising from enhanced ember generation associated with VLS. The enhanced pyroconvection generated by eruptive fire behaviour would likely have a similar effect on the long-range ember transport.

\section{DISCUSSION AND CONCLUSIONS}

The current Standard for construction in bushfire prone areas (AS3959) is not consistent with the current state of the science of bushfires. Recent research has indicated that the quasi-steady assumption is likely to be generally invalid when considering the type of fire behaviour that is most likely under conditions of FFDI $>$ 80 , and particularly in regions prone to specific modes of dynamic fire propagation like VLS and flame attachment. While the provisions for embers and convective heating in AS3959 were perhaps adequate based on the available knowledge 10-15 years ago, much more accurate provisions could be implemented based on more recent research.

To summarise, the main shortcomings of the Standard centre on the following points:

- It is based entirely on the assumption that fires propagate in a quasi-steady manner; 
- It is predicated on the notion that the main cause of house loss is radiant heat exposure;

- It factors in the effect of embers in an over-simplistic way via an assumed relationship with radiant heat exposure.

Specifically, the Standard provides identical ember mitigation measures across all BALs (other than BAL Low, which has no requirements). However, as the Ginninderry case study demonstrates, embers would be much more likely to originate from the areas to the northwest, and would have greatest impacts on the northwest edge, at distances that possibly exceed the $100 \mathrm{~m}$ exclusions distance. As a consequence, the issues raised present a number of questions about the adequacy of the design and construction guidelines in AS3959 and the validity of risk management strategies that use AS3959 as their basis. They also offer a basis for more dedicated review and refinement of AS3959.

\section{ACKNOWLEDGEMENTS}

This work was supported by consultancy funding from the Ginninderra Falls Association.

\section{REFERENCES}

Bushfire CRC. (2009). Victorian Bushfires 2009 Research Taskforce - Final Report. Bushfire Cooperative Research Centre. Available from: http://www.bushfirecrc.com/managed/resource/bushfire-crcvictorian-fires-research-taskforce-final-report.pdf

Cruz, M.G., Sullivan, A.L., Gould, J.S., Sims, N.C., Bannister, A.J., Hollis, J.J., Hurley, R.J. (2012). Anatomy of a catastrophic wildfire: the Black Saturday Kilmore East fire in Victoria, Australia. Forest Ecology and Management, 284, 269-285.

Dold, J. W., Zinoviev, A. (2009). Fire eruption through intensity and spread rate interaction mediated by flow attachment. Combustion Theory and Modelling 13, 763-793.

McRae, R.H.D., Sharples, J.J., Fromm, M. (2015). Linking local wildfire dynamics to pyroCb development. Natural Hazards and Earth System Sciences, 15, 417-428.

Mills, G.A., McCaw, L. (2010). Atmospheric Stability Environments and Fire Weather in Australia extending the Haines Index. CAWCR Technical Report No. 20.

NSW RFS (2006). Planning for Bush Fire Protection. A guide for Councils, Planners, Fire Authorities and Developers. New South Wales Rural Fire Service and Department of Planning.

Peace, M., McCaw, L., Mills, G. (2012). Meteorological dynamics in a fire environment; a case study of the Layman prescribed burn in Western Australia. Australian Meteorological and Oceanographic Journal 62, 127-141.

Roberts, M.E., Sharples, J.J., Rwalinson, A.A. (2017). Incorporating ember attack in bushfire risk assessment: a case study of the Ginninderry region. These proceedings.

Sharples, J.J., Cary, G.J., Fox Hughes, P., Mooney, S., Evans, J.P., Fletcher, M.S., Fromm, M., Grierson, P.F., McRae, R., Baker, P. (2016). Natural hazards in Australia: extreme bushfire. Climatic Change, 139, 85-99.

Sharples, J.J. (2009). An overview of mountain meteorological effects relevant to fire behaviour and bushfire risk. International Journal of Wildland Fire, 18, 737-754.

Sharples, J.J., McRae, R.H.D., Wilkes, S.R. (2012). Wind-terrain effects on the propagation of wildfires in rugged terrain: fire channelling. International Journal of Wildland Fire 21, 282-296.

Simpson, C., Sharples, J., Evans, J., McCabe, M. (2013). Large eddy simulation of atypical wildland fire spread on leeward slopes. International Journal of Wildland Fire 22, 282-296.

Simpson, C., Sharples, J.J., Evans, J.P. (2016). Sensitivity of atypical lateral fire spread to wind and slope. Geophysical Research Letters, 43, 1744-1751.

Standards Australia (2009). AS 3959, Australian Standard for construction of buildings in bushfire prone areas. Standards Australia, Sydney.

Viegas, D. (2005). A mathematical model for forest fires blow-up. Combustion Science and Technology 177, $27-51$. 